\title{
RESUMO
}

ISSN Digital: 2316-381X

ISSN Impresso: 2316-3321

DOI: 10.17564/2316-381X.2020v8n2p149-161

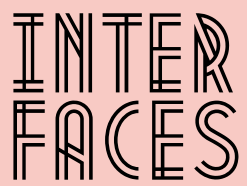

CIENTÍFICAS

\section{A ATA NOTARIAL E OS POSSIVEIS RISCOS À SEGURANÇA JURÍDICA EM TEMPOS DE FAKE NEWS}

\section{THE NOTARIAL ACT AND POSSIBLE RISKS \\ TO FAKE LEGAL SECURITY NEWS}

LA ACTA NOTARIAL Y LOS POSIBLES RIESGOS A LA SEGURIDAD JURIIDICA EN TIEMPOS DE NOTICIAS FALSAS
Cid Silveira da Silva ${ }^{1}$

Marlton Fontes Mota ${ }^{2}$

Ellen de Oliveira Fumagali ${ }^{3}$

Diogo de Calasans Melo Andrade ${ }^{4}$
A competência funcional da ata notarial é a de registrar o modo de existir de algum fato atestado ou documentado, mediante lavratura por tabelião. Em tempos de tecnologia digital, a busca pela segurança jurídica coloca a ata como um forte elemento de prova no processo. 0 objetivo da pesquisa é a análise a respeito da possibilidade de violações ao princípio da segurança jurídica pelo uso de atas notariais para o registro de fatos e informações digitais, em tempos de fake news. Por meio da pesquisa qualitativa de cunho exploratório, observando-se o contexto bibliográfico sobre o tema central do trabalho, busca-se compreender as motivações no uso da ata notarial. A pesquisa propõe a reflexão sobre a incidência de conteúdos e informações falsas, que são publicados em sites da internet e em rede social, também sobre os possíveis riscos advindos para o manejo da ata notarial como elemento de prova no processo. Os resultados apresentados deverão ser objeto de análise e reflexão, identificando a força probatória da ata.

\section{PALAVRAS-CHAVE}

Ata Notarial. Fake News. Segurança Jurídica. 


\section{ABSTRACT}

The functional competence of the notarial act is to record the way of existing of some fact can be attested or documented, by recording by notary. In times of digital technology, the search for legal security places the minutes as a strong piece of evidence in the process. The objective of the research is the analysis regarding the possibility of violations to the principle of legal certainty by the use of notarial records for the recording of facts and digital information, in times of fake news. Through the exploratory qualitative research, observing the bibliographical context on the central theme of the work, it is sought to understand the motivations in the use of notarial certificates. The research proposes to reflect on the incidence of false content and information, which are published on Internet and social networking sites, and on the possible risks arising from the handling of notarial certificates as evidence in the process. The results presented should be analyzed and reflected, identifying the probative value of the act.

\section{KEYWORDS}

Notarial Act. Fake News. Legal Security.

\section{RESUMEN}

La competencia funcional de las actas notariales es registrar la forma en que un hecho puede ser atestiguado o documentado, redactando por un notario. En tiempos de tecnología digital, la búsqueda de seguridad jurídica pone la acta como una prueba sólida en el proceso. El objetivo de la investigación es analizar la posibilidad de violaciones del principio de seguridad jurídica mediante el uso de actas notariales para registrar hechos e información digital, en tiempos de noticias falsas. A través de la investigación cualitativa de carácter exploratorio, observando el contexto bibliográfico sobre el tema central del trabajo, buscamos comprender las motivaciones en el uso de actas notariales. La investigación propone una reflexión sobre la incidencia de contenido e información falsos, que se publican en sitios de Internet y en una red social, y sobre los posibles riesgos derivados del manejo de actas notariales como demuestra en el proceso. Los resultados presentados deben estar sujetos a análisis y reflexión, identificando la fuerza probatoria de los minutos.

\section{PALABRAS CLAVE}

Actas notariales; Noticias falsas; Seguridad jurídica. 


\section{INTRODUÇ̧̃̃o}

A incorporação do Direito às novas tecnologias se deu de forma lenta por haver um receio quanto à inserção dessa dinamicidade ao Direito estático. Faz-se necessária a sua adequação à era da informatização, visando aplicar as inúmeras vantagens oriundas do ciberespaço na busca da verdade real dos fatos, numa relação jurídico-processual. Nas relações interpessoais mediadas pela tecnologia digital, o papel do Direito torna-se de extrema relevância para a solução de possíveis conflitos, inclusive para consolidar a apreciação do conteúdo probatório apresentado pelas partes no processo, que efetivamente, poderá ser oriundo das informações virtuais contidas no ambiente digital.

Nesse sentido o Código de Processo Civil (Lei 13.105/2015) legitimou em seu artigo 384 a ata notarial, já utilizada anteriorment, e amparada pela jurisprudência. De acordo com o citado Código, a ata notarial é instrumento público redigido por tabelião, atribui presunção de veracidade aos fatos nela contidos, sendo documento dotado de fé pública. De acordo com o legislador, ela é destinada a garantir a publicidade, autenticidade, segurança e eficácia dos atos jurídicos, vem sendo amplamente utilizada para registrar fatos e dados em sites da internet, visto a facilidade de perda dessas informações o interessado busca por meio da ata resguardar provas para uma futura lide.

Com vistas a tornar o tema elucidativo, o presente trabalho tem como propósito promover a reflexão sobre a possibilidade de violações ao princípio da segurança jurídica pela utilização de atas notariais, cujo conteúdo é atestado pelo escrivão, quem tem fé pública. Além de preconizar a celeridade e resguardar o conteúdo que será elemento da prova, a ata notarial traz a segurança jurídica como requisito na sua formação. Com o objetivo de esclarecer quanto à possibilidade do uso da ata notarial para assegurar a veracidade do conteúdo publicado em sites da internet e rede social, a pesquisa propõe a reflexão sobre os riscos dos chamados fake news, ou notícias falsas, trazendo à baila a preocupação sobre a segurança jurídica.

Em virtude da crescente evolução da tecnologia e a intensificação da busca pela ata notarial para comprovar crimes virtuais que podem se perder no tempo, essa pressa em assegurar a prova, sem analisar com cautela o conteúdo, leva à possibilidade de estar dando fé pública a um material que pode ser falso. Visto esta problemática cabe se perguntar se o tabelião de notas está preparado para identificar sites e conteúdos inverídicos e se segue normas e requisitos para evitar dar fé pública a um material probatório que poderá desaparecer ou ser modificado, impossibilitando a realização de uma perícia para atestar sua autenticidade.

Assim sendo, a elaboração deste trabalho busca elucidar os seguintes questionamentos: a) quais os requisitos para requerimento da elaboração da ata notarial? b) o tabelião é habilitado para avaliar veracidade do conteúdo da internet que dará fé pública? c) a celeridade pode ser um elemento prejudicial à composição da veracidade do conteúdo na Ata?

Para tanto, a metodologia utilizada embasou-se, principalmente, na exploração das fontes bibliográficas por meio da coleta de livros, artigos, revistas cientificas, teses, relatórios de pesquisa sobre o tema em análise na plataforma digital Scielo, na biblioteca física e digital da Universidade Tiradentes e websites. 0 método aplicado fora o dedutivo, tal método permite uma análise às pesquisas já realizadas sobre a temática a ser estudada, também, possibilita que um tema seja analisado sob diferentes perspectivas, resultando em novas conclusões. 
O trabalho dividiu-se em três capítulos específicos, sendo abordado no primeiro segmento a conceituação da ata notarial, a forma de elaboração e os principais princípios norteadores. No segundo capítulo buscou-se evidenciar a respeito da força probante da ata notarial no processo, mostrando o quão carregado de convencimento é o seu conteúdo, quando posta em juízo, devido sua presunção de veracidade e a fé pública que lhe é atribuída pelo notário. 0 terceiro capítulo foi dedicado a esclarecer quanto à temeridade das consequências que vêm acompanhadas às fakes news e a possibilidade de tais feitos, usando como meio a ata notarial, influenciarem as decisões judiciais de maneira a prejudicar uma parte no processo.

\section{CONCEITO E REQUISITOS DA ATA NOTARIAL}

Não há uma conceituação formal sobre a ata notarial no ordenamento jurídico pátrio, mesmo após sua positivação pela Lei n 13.105/2015, que institui o novo Código de Processo Civil (CPC). A definição do artigo 384/CPC está mais para o objeto da ata notarial do que seu conceito, o qual aduz: “A existência e o modo de existir de algum fato podem ser atestados ou documentados, a requerimento do interessado, mediante ata lavrada por tabelião".

Assim, a definição ficou a cargo da doutrina, que a realiza de forma simplória. Existe uma carência de obras que tratem de tal instituto de forma ampla e meticulosa. Elpídio Donizetti (2017, p. 643) traz a seguinte definição de ata notarial “[...] é o instrumento formalizado por tabelião para constatar a realidade de um fato que ele presenciou ou do qual tomou conhecimento, sem qualquer emissão de opinião pessoal' (Grifo do autor).

Imperioso destacar que a ata notarial é meio de prova lavrado com exclusividade pelo tabelião de notas, sendo este um depositário da fé pública e que atesta a veracidade dos conteúdos lavrado no instrumento, utilizando a sua percepção, por meio dos sentidos, visão, audição. 0 exercício dessa atividade pelo escrivão é realizado de forma imparcial, tendo a finalidade de resguardar informações e atos que podem desaparecer ou que, por outro meio não seria possível preservar.

Segundo Loureiro (2017, p. 1204) ata notarial “[...] é o instrumento público que tem por finalidade conferir fé pública a fatos constatados pelo tabelião, por meio de qualquer de seus sentidos, destinando-se à produção de prova pré-constituída”. Portanto, a ata notarial tem como finalidade principal a constituição de prova para utilização em uma futura lide seja na esfera judicial ou extrajudicial e até em processos administrativos.

Apesar da conceituação restrita da maioria dos doutrinadores, percebe-se que convergem no sentido de que a ata notarial se trata de um instrumento público, cuja competência para elaboração é exclusiva do tabelião de notas e que tem por objeto a narrativa de fatos que são lhes apresentados, de forma imparcial. Pode ser objeto da ata notarial, de forma residual, tudo que não puder ser objeto da escritura pública. De acordo com a legislação competente, a diferença entre ambas é que nesta última há a declaração de vontade e na outra essa declaração é ausente.

Quanto à forma para elaboração da ata notarial, por enquanto, inexiste regulamentação federal nesse sentido, ficando a cargo de cada Estado regular a questão. Não há também legislação federal 
que regule sobre os elementos que devem estar presentes na ata notarial, sendo usados, com algumas adaptações, os requisitos destinados às escrituras públicas.

Tais requisitos estão dispostos no artigo 215 e parágrafos do Código Civil, um deles é a redação em língua portuguesa, admitindo-se algumas expressões estrangeiras em casos específicos. Isto é o que acontece quando a ata notarial se prestar à constatação de conteúdo em sítio eletrônico. Há também como requisito o requerimento e a capacidade natural em requerer da parte interessada, dentre outros.

A atividade notarial deve seguir os princípios básicos que regem a Administração Pública. E esses princípios se revelam como o conjunto de regras e preceitos a serem seguidos em operações jurídicas. De acordo com a sua contextualização cartorária, os princípios norteadores da ata notarial de maior relevância são a segurança jurídica e a fé pública. A segurança jurídica irradia para todos os ramos do direito, não é típico apenas ao tabelionato. Segundo Deserti (2016, p. 132), esse princípio é “[...] um pilar de sustentação de toda a atividade notarial e registral e até mais do que isso, um totem da atividade notarial. 0 cartório por si só já representa segurança para a sociedade”.

A segurança jurídica é um princípio intrínseco à atividade do notário, pois a sociedade ao buscar o Cartório de Registro para lavrar ou autenticar documentos, o faz com a pretensão, justamente, de obter a credibilidade conferida aos instrumentos públicos. Cabe ao notário garantir a segurança jurídica, evitando dar legitimidade ou autenticar documentos contrários à lei, para Loureiro (2017, p. 1032) cabe ao notário garantir a segurança e a legalidade na realização do seu trabalho.

Daí advém o princípio da fé pública, o notário, delegado da administração, de acordo com determinação constitucional (art. 236, CF/88), atribui, por meio de seus atos, a presunção de autenticidade e veracidade aos documentos registrados que só podem ser questionados judicialmente.

O ordenamento jurídico prevê esse princípio no NCPC/ 2015 nos artigos 374, IV e 405, onde define ser desnecessário provarem-se os fatos que possuem presunção de veracidade e ainda que “[...] o documento público faz prova não só da sua formação, mas também dos fatos que o escrivão, o tabelião, ou o funcionário declarar que ocorreram em sua presença." Bem como aduz também a Lei dos Registros Públicos (8.935/1994) nos arts. $3^{\circ}, 6^{\circ}$, III e $7^{\circ}$, III, IV e V a previsão do princípio da fé pública ou notoriedade ao estabelecer que o tabelião ou notário é o responsável para autenticar fatos, reconhecer firmas e autenticar cópias.

A fé pública, de forma notória, exprime a credibilidade dada pela sociedade na veracidade e autenticidade desses documentos, tendo como consequência a preservação segurança jurídica, tanto na resguarda dos fatos e documentos como na confiabilidade que a coletividade deposita nas instituições públicas. Loureiro (2017, p. 1022) afirma que a fé pública atribui aos notários (e outros agentes públicos) "a verificação ou atestação de fatos, atos e contratos ocorridos ou produzidos em sua presença ou com sua participação”.

\section{VALOR PROBATÓRIO DA ATA NOTARIAL}

O Código de Processo Civil de 2015 trouxe várias novidades aos meios de provas. Deu a ata notarial o status de meio típico de prova, tornando seu uso na prática ainda mais importante. É direito e exer- 
cício de qualquer cidadão se utilizar dos meios lícitos e cabíveis para a produção de provas, direito esse que é garantido pelo sistema processual brasileiro.

A ata notarial vem sendo utilizada com maior frequência, pois, propicia a elaboração e materialização de prova, tem fácil acesso pelo interessado, possibilitando, na sua abrangência de conteúdo, a fé pública que lhe confere a segurança e autenticidade suficientes à pretensão do objeto, além de possuir uma grande significância em relação às outras provas, quando posta em juízo.

A utilização da ata notarial como meio de prova teve maior relevância com a ascensão do uso da internet, decorrente da expansão no processo de comunicação e compartilhamento de fotos, dados e vídeos, que, por vezes, provocam violações a direitos. Tornando necessária, nessa perspectiva, a materialização das provas oriundas dos fatos e atos praticados no meio virtual, com a finalidade de preservação desses eventos para evitar o perecimento do seu conteúdo.

Os processos judiciais cujos fatos ou atos foram praticados por pessoa física ou jurídica e que ocorreram no âmbito da internet têm gerado um grande desafio para o sistema jurídico brasileiro, devido à volatilidade do material produzido, que pode a qualquer momento se perder. Nesse sentido a ata notarial tem obtido maior notoriedade e espaço como meio probante. Alguns desses exemplos no uso da ata notarial como elemento probatório são destaque, com a exposição do julgado exarado pelo c. Tribunal de Justiça do Estado do Rio Grande do sul, a saber:

\begin{abstract}
EMENTA
AGRAVO DE INSTRUMENTO. ALIMENTOS. EXONERAÇÃO. Conforme jurisprudência dominante, uma vez atingida a maioridade, pelo beneficiário, os alimentos deixam de encontrar seu fundamento no dever de sustento dos pais para com os filhos menores (art. 1.566, inc. IV, do CCB) e passam a amparar-se na obrigação existente entre parentes (art. 1.694 e seguintes do CCB), desaparecendo, a partir daí, a presunção de necessidade. No caso, conforme consta de cópia de ata notarial juntada, a agravada possui um blog, onde refere contar com 19 anos e ter um filho, o que é confirmado pelas postagens na sua página do Facebook. [...]. DERAM PROVIMENTO. UNÂNIME. (Agravo de Instrumento Nº 70076575331. Oitava Câmara Cível, Tribunal de Justiça do RS, Relator: Luiz Felipe Brasil Santos, Julgado em 26/04/2018). (TJ-RS - Al: 70076575331 RS, Relator: Luiz Felipe Brasil Santos, Data de Julgamento 26/04/2018, Oitava Câmara Cível, Data da Publicação: Diário de Justiça do dia 02/05/2018. Sem grifos no original).
\end{abstract}

A adoção expressa da ata notarial no novo CPC busca dar celeridade processual, podendo registrar o ato ou fato que se desejar provar, sem a necessidade de ir a juízo requerer a produção antecipada de provas. Como já explanado, a ata notarial é registrada, a requerimento do interessado, exclusivamente pelo tabelião, por meio de narrativa de fatos, dados, documentos, dentre outros.

Esse registro é verificado pelos sentidos e percepção do tabelião, que confere a ata registrada, a fé pública e comprovação da sua autenticidade. Nesses termos, a ata notarial é o instrumento mais adequado para materializar o ato ou o fato, com o propósito de resguardar o direito do interessado. Vale salientar que a fé pública conferida pelo tabelião recai sobre o que está verificando, anotando tudo que lhe é apresentado expressamente, essa fé pública não incide sobre o conteúdo de fato, esse pode ser inverídico. 
Lembrando os ensinamentos de Câmara (2017, p. 215), a ata notarial tem grande impacto no aspecto instrutório do processo e, quando posta em juízo, devido sua fé pública, transfere a outra parte o ônus da prova "[...] a ata notarial faz prova suficiente daquilo que o notário declare ter presenciado, o que acaba por fazer incidir sobre a parte contrária o ônus da contraprova”. Esse instrumento, portanto, possui forte carga de convencimento, agregando força probante aos fatos que materializa. Nesse sentido cabe ao réu então comprovar a falsidade das alegações do autor, devido à fé pública que é consignada ao conteúdo destacado no bojo da ata.

O amparo jurídico da ata notarial está no artigo 384, também, no artigo 405/CPC, os quais esclarecem que o documento público faz prova, não só na sua formação como também nos fatos em que 0 escrivão, o tabelião ou servidor declararem ter ocorrido em sua presença.

o Código Civil traz disposto em seus artigos 215 e 217 a fé pública, a prova plena e a força probante os documentos lançados em ata notarial lavradas por tabelião. Não há nenhum dispositivo legal que impeça o uso de prova eletrônica devidamente coletada e resguardada.

Em virtude de sua força probante e a relevância que tem com relação às demais provas é de suma importância a cautela na sua elaboração. Especialmente, pelo fato de a ata notarial não ter requisitos próprios, usar subsidiariamente as normas gerais da escritura pública, devido suas especificidades, principalmente quando do registro de informações de sites da internet.

Ainda, não tendo requisitos de segurança para verificação da veracidade dos dados do site, o tabelião, ao conferir sua percepção à ata notarial, materializará o registro de dados, dando-lhes autenticidade e fé pública, nessa situação poderá estar violando o princípio da segurança jurídica e da fé pública. Nesse contexto, a credibilidade conferida pela sociedade no serviço público do notário, bem como na lisura das decisões judiciais podem ficar abaladas. A reflexão sobre essas condições está configurada no capítulo seguinte.

\section{AS INFORMAÇÕES VIRTUAIS FALSAS E A INSEGURANÇA DO MEIO DIGITAL}

Sabe-se que é perfeitamente possível a disseminação de conteúdos falsos ou alterados que levam a uma pessoa comum a crer que determinado vídeo, imagem ou texto seja verídico. Fato que tem ocorrido com muita frequência, isso pôde ser visto claramente nas últimas eleições presidenciais, tanto no Brasil como nos EUA. O alastramento de notícias falsas favorece a desordem intelectual on-line e em alguns casos contribuem para consequências irreversíveis no mundo real.

Devido ao exponencial número de usuários, vem crescendo a cada ano a quantidade de pessoas que aderem a comunicação via rede. Branco (2017, p. 51-61) acrescenta que "por meio da internet, as distâncias encolheram, tornou-se mais rápida e barata a comunicação, [...] novos modelos de negócio surgiram, democratizou-se o caminho da liberdade de expressão".

Segundo dados divulgados pelo Comitê Gestor da Internet no Brasil só no ano de 2017, o acesso à Internet nos domicílios no Brasil chegou a $61 \%$ das residências, totalizando 42,1 milhões de lares conectados. Percebe-se que, nos últimos anos, tem aumentado significativamente o número de usu- 
ários de redes sociais e aplicativos de comunicação. Como consequência disso tem-se a proliferação de informações falsas e violações cometidas via rede mundial de computadores.

Por suas características amplas e abrangentes e a crescente evolução da tecnologia digital, a ata notarial tem sido frequentemente utilizada como um instrumento de comprovação em demandas judiciais, especialmente, no que diz respeito ao processo de certificação de material, advindo do meio eletrônico. É percebido o aumento no volume de demandas decorrentes das interrelações em espaços virtuais, isso se justifica, também, pelo crescente acometimento de crimes cibernéticos e de fraudes virtuais, que são oriundos, em regra, da exposição de dados pessoais e agressões à honra e à imagem.

O protagonismo concebido pelo espaço digital promove, em contrapartida, o "anonimato" dos seus usuários, desencadeando uma diversidade de informações que, geralmente, criam dificuldades em perceber a sua fonte e esses são os principais fatores que têm dado uma significativa relevância à ata notarial. Afinal, a fluidez e o compartilhamento em tempo presente das informações que circulam na rede mundial de computadores, fragilizam as possíveis pretensões daqueles que buscam reparações judiciais, a partir da coleta desse conteúdo.

Com respaldo no Marco Civil da Internet (Lei 12.965/14), valendo-se da ata notarial como principal meio de prova, as ações para retirada do ar, criminalização e responsabilização de publicações em blogs, sites e redes sociais só vem aumentando no país. O Marco Civil da Internet traz garantias e princípios para utilização da internet, direitos e deveres a serem observados pelos usuários. Com isso oportuniza àqueles que se sentirem lesados a buscar, via judiciário, a efetivação dos seus direitos.

Nos últimos cinco anos, segundo o Colégio Notarial do Brasil - Seção São Paulo (CNB/SP, 2018), a busca por registro de atas notariais subiu $94 \%$ em todo o país. Esse crescimento exacerbado do uso da ata notarial como meio probante, exclusivo, para atestar conteúdos de sites na internet pode trazer sérios problemas ao sistema jurídico, pois, as atas não estão isentas dos efeitos danosos das Fakes News. Conforme predito no texto, não há procedimentos de seguranças a serem seguidos na elaboração da ata notarial, principalmente em se tratando de dados digitais, além do fato de que, o trato de informações virtuais requer a experiência que, por vezes, não acomete ao tabelião na habitualidade do seu ofício.

Num cenário predominantemente digital, se o tabelião não possuir certo domínio sobre a navegação em espaços virtuais, poderá ter dificuldades em reconhecer o conteúdo ou informações falsas que tenham a aparência de verdadeiras. Embora a sua função seja a de registrar o fato ou ato, na forma em que se apresentam, os riscos são presentes.

O aumento significativo pela busca do registro de ofensas via rede digital, para provar o conteúdo de determinada página na Internet é devido à volatilidade das informações publicadas nessa rede mundial de computadores. A ata notarial, positivada no CPC/2015, vem como uma forma de resguardar provas para uma futura ação de reparação de danos por violação de direitos contra cibercriminosos. Segundo Câmara (2017, p. 215), o conteúdo de páginas eletrônicas, na internet, pode ser facilmente alterado.

A partir da utilização diária e expressiva da internet e sua disseminação na sociedade, todos os tipos de conteúdos são criados e compartilhados em uma velocidade surpreendente. Nas redes digitais tudo se transforma o tempo todo, em tempo real milhões de imagens se formam e essas informações estão ao alcance dos olhos e do clicar dos dedos sobre os aparatos móveis. 
Porém, discute-se sobre a veracidade das informações lançadas no ciberespaço, pois, nesse mundo virtualizado o que se vê, nem sempre reflete a realidade e tende, ao ser criado/alterado pelo usuário das redes, um caminho para ganhar likes (manifestações favoráveis sobre o conteúdo), ou apenas para atrair olhares curiosos que repassam tais informações, sem ao menos conferir sua veracidade.

0 repasse de informações inverídicas sempre existiu no processo comunicacional virtual, porém o boom que fez gerar uma preocupação ainda maior nos meios de comunicação e entre operadores do direito e juristas, veio com visibilidade de notícias falsas, proporcionada pelas eleições de 2018 no Brasil e nos EUA. Muitas informações distorcidas sobre os candidatos aos cargos eletivos, estavam sendo criadas com o intuito de denegrir a imagem e a honra dos pretendentes aos cargos eletivos, promovendo, inclusive, o levantamento de números em pesquisas de opinião inexistentes, gerando prejuízos em massa e por vezes irreparáveis, consequências da propagação das chamadas fake news.

Sob inúmeras provocações em demandas competentes, os tribunais brasileiros se posicionaram no combate às informações inverídicas dispostas nas vastas matérias que estavam sendo espalhadas pelas redes sociais. Fato este que serviu para que todos tivessem a ideia do quão prejudicial a disseminação desses conteúdos poderia ser na geração de conflitos.

A partir dessa perspectiva, poderiam, também, ultrapassar o mundo virtual alcançando o mundo real. Trazendo a problemática não só no nível político, mas retratando-a em todas as outras áreas, há uma expectativa de que pode gerar uma certa insegurança jurídica quando se trata da propagação de informações que distorcem a realidade dos fatos, circulantes nas redes de computadores. Caso essas informações precisem ser materializadas como provas em demandas judiciais, por meio da ata notarial, em tempos de Fake News, cabe a reflexão sobre o fato de que os tabeliães poderão estar suscetíveis ao acometimento de equívocos.

Cabe levar à reflexão sobre a necessária preparação específica dos tabeliões, para a adoção de medidas protetivas suficientes, que permitam a integridade das informações descritas em atas, garantindo-se a verdade real, que é uma das finalidades do processo judicial. Sobre a contextualização do tema, cabe a colação de julgado, onde há o destaque a respeito da projeção das fake news, circulantes nas redes virtuais, a saber:

\section{Ementa}

ELEIÇÕES 2018. REPRESENTAÇÃO POR DIVULGAÇÃO DE PESQUISA FRAUDULENTA E PROPAGANDA ELEITORAL ANTECIPADA. POSTAGEM EM BLOG. DIVULGAÇÃO DE SUPOSTA PESQUISA ENTERNA NÃO REGISTRADA. PRÉ-CANDIDATOS AO GOVERNO DO ESTADO. PROPAGANDA ANTECIPADA NEGATIVA E POSITIVA. NÃO COFIGURADO. FAKE NEWS. POSTAGEM INVERÍDICA. PROCEDÊNCIA PARCIAL DA REPRESENTAÇÃO. I. Não se pode atribuir a qualquer tipo de publicação o caráter de pesquisa para fins eleitorais, ainda que contenham preferência por determinado candidato em pleito eminente, inclusive com indicação de percentual de votos, ante a necessidade de demonstrar que tais informações ou dados tenham sido efetivamente obtidos por meio de inquirição de pessoas em determinada área, com a utilização de um procedimento eminentemente técnico. [...] V. Ausência de prova da veracidade da notícia publicada, ou seja, prova de que referidas pesquisas internas realmente existiram, entendendo tratar-se, sim, de notícia falsa 
(fake news). VI. Procedência parcial da representação. [...]. (TER-MA - RP:060003848 SÃO LUÍS - MA Relator: JÚLIO CÉSAR LIMA PRASERES, Data de Julgamento: 01/08/2018, Data de Publicação: DJ - Diário de justiça, Tomo 149, Data 13/08/2018, Página 63. Sem grifos no original).

Ao tabelião cabe conferir com os sentidos dados e fatos que irá registrar e dar garantias quanto à autenticidade dos dados por ele verificados, mas não há uma preparação específica dos notários para uma percepção peculiar sobre os conteúdos eletrônicos. Por essa falta de parâmetros de segurança a serem seguidos e a verossimilhança dos websites falsos, tais fatores podem gerar falhas na verificação do conteúdo da página da internet a ser atestada, registrando por meio de ata notarial matéria falsa como um ato ou fato de potencial veracidade e consequentemente gerar insegurança jurídica.

Devido os avanços da tecnologia, que possibilitam a projeção e a alteração dos conteúdos em sítios eletrônicos, em contrapartida ao aumento excessivo de registro de ata notarial e a possível má fé do interessado, podem proporcionar fatores que gerem insegurança jurídica, especialmente, quando a decisão judicial se pautar em ato ou fato materializados na ata notarial, que são extraídos do mundo das relações interpessoais virtualizadas.

\section{CONSIDERAÇÕES FINAIS}

Na proposta do texto verificou-se sobre a relevância no uso da ata notarial como meio de prova nas demandas judiciais, destacando a sua aplicação específica no meio digital, em virtude da dinamicidade e a fragilidade no registro de atos de fatos no meio eletrônico. A ata notarial surgiu como um instrumento para assegurar a preservação desse material probatório, que sem esse registro, provavelmente se perderia no tempo, além de promover a credibilidade e durabilidade daquele conteúdo probatório. Em virtude dessas suas características, a ata notarial tem sido bastante usada para o resguardo de provas com a finalidade de ser usada num possível processo judicial.

Foi identificado na pesquisa que a ata notarial não possui parâmetros próprios para sua elaboração, sendo utilizados, subsidiariamente, os requisitos da escritura pública. Também não há normas técnicas de segurança a serem seguidas pelos tabeliães no registro da ata, que para garantirem a feitura da ata, usam apenas dos seus sentidos e percepção para lavrar fatos e dados que são thes apresentado pelo interessado.

Com base em todos os dados apresentados sobre a ata notarial, é possível concluir que há a possibilidade de ocorrências sobre os dados assegurados naquele instrumento público, que podem ser envolvidos por atos e fatos questionáveis, em relação à inteireza da realidade que pretendem assegurar. Incorrendo em falhas quanto à elaboração da ata notarial, a partir de supostas informações inverídicas, e que, por consequência poderiam macular o uso como meio probante.

0 texto propõe a reflexão sobre a influência das informações falsas, as chamadas Fake News, que circulam abundantemente no universo das vias digitais. Sob essa ameaça, faz-se necessário atentar para o cumprimento do princípio da segurança jurídica, a partir da implementação de normas que 
possam assegurar a inteireza do registro de dados da internet na ata notarial, sob o aspecto da maior veracidade possível das suas fontes.

É possível compreender a importância do tema proposto, pois, em várias circunstâncias, os próprios meios de comunicação em massa foram vítimas de notícias que não correspondiam à realidade dos fatos. Exemplo marcante foi o caso das notícias veiculadas durante o processo eleitoral de 2018 no Brasil e nos EUA, que foi destacado na presente pesquisa.

Portanto, diante dos riscos noticiados, torna-se importante a capacitação dos tabeliães e seus substitutos, no sentido de promover-lhes uma maior preparação técnica sobre o trato das tecnologias de informação e comunicação no espaço virtual, com a finalidade de garantir uma maior segurança jurídica à população a respeito dos atos de fatos materializados na ata notarial. Visto que a elaboração desse instrumento público, pode ser vitimada por informações e dados falsos que podem gerar prejuízos incalculáveis para a própria sociedade, além de predizer sobre insegurança jurídica, bem como a possibilidade de descrédito nas instituições públicas.

\section{REFERÊNCIAS}

BRANCO, Sérgio. Fake news e os caminhos para fora da bolha. Interesse Nacional, São Paulo, ano 10, n. 38, p. 51-61, ago.-out. 2017.

BRASIL. Planalto. Constituição 1988. Constituição da República Federativa do Brasil. BrasíliaDF: Senado Federal. Disponível em: http://www.planalto.gov.br/ccivil_03/constituicao/ constituicaocompilado.htm. Acesso em: 26 dez. 2019.

BRASIL. Planalto. Lei $\mathbf{n}^{\mathbf{0}}$ 12.695, de 23 de abril de 2014. Estabelece princípios, garantias, direitos e deveres para o uso da Internet no Brasil. [S. l.], 23 abr. 2014. Disponível em: http://www.planalto. gov.br/ccivil_03/_ato2011-2014/2014/lei//12965.htm. Acesso em: 25 dez. 2019.

BRASIL. Planalto. Lei no 13.105, de 16 de março de 2015. Código de Processo Civil. Disponível em: http://www.planalto.gov.br/ccivil_03/_ato2015-2018/2015/lei/l13105.htm. Acesso em: 13 jan. 2020.

BRASIL. Planalto. Lei n 10.406, de 10 de janeiro de 2002. Institui o Código Civil. 10 jan. 2002.

Disponível em: http://www.planalto.gov.br/ccivil_03/LEIS/2002/L10406.htm. Acesso em: 5 dez. 2019.

CÂMARA, Alexandre Freitas. 0 novo processo civil brasileiro. 3. ed. São Paulo: Atlas, 2017.

COMITÊ GESTOR da internet no Brasil (cgi.br). Acesso à Internet por banda larga volta a crescer nos domicílios brasileiros. 24 out. 2017. Disponível em: https://cgi.br/noticia/releases/acesso-ainternet-por-banda-larga-volta-a-crescer-nos-domicilios-brasileiros/. Acesso em: 20 dez. 2019. 
COLÉGIO NOTARIAL do Brasil - seção São Paulo (CNB/SP). Cresce registro de atas notariais sobre crimes virtuais. [S. l.], 16 out. 2018. Disponível em: http://www.cnbsp.org.br/index.php?pG=X19leG liZV9ub3RpY2lhcw==\&in=MTY5MzE=\&filtro=1. Acesso em: 22 dez. 2019.

DESERTI, Bruna Sitta. Ata notarial como meio de prova. 2016. 132f. Dissertação (Mestrado em Direito) - Faculdade de Ciências Humanas e Sociais, Universidade Estadual Paulista "Júlio de Mesquita Filho", Franca, 2016.

DONIZETTI, Elpídio. Curso didático de direito processual civil. 20. ed. rev. atual. ampl. São Paulo: Atlas, 2017.

GONÇALVES, Victor Hugo Pereira. 0 temerário uso da ata notarial para a formação de provas digitais. 25 jan. 2018. Disponível em: https://www.conjur.com.br/2018-jan-25/victor-goncalvestemerario-uso-ata-notarial-provas-digitais. Acesso em: 28 jan. 2020.

LANGE, Rafaela Johnke. Considerações acerca da ata notarial como meio de prova. Disponível em: tcconline.utp.br/?p=23718. Acesso em: 25 dez. 2019.

LOUREIRO, Luiz Guilherme. Registros Públicos: teoria e prática. 8. ed. rev., atual e ampl. Salvador: Editora Juspodivm, 2017.

MARANHÃO. Tribunal Regional Eleitoral do Estado do Maranhão (TRE-MA). Representação: RP 060003848. São Luís-MA. Relator: Júlio César Lima Praseres. DJ 13/08/2018.Disponível em: http:// www.tre-ma.jus.br/jurisprudencia. Acesso em: 4 jan. 2019.

MEDINA, José Miguel Garcia. Direito processual civil moderno. Livro eletrônico. José Miguel Garcia Medina. 3 ed. São Paulo: Editora Revista dos Tribunais, 2017.

RIO GRANDE DO SUL. Tribunal de Justiça do Estado do Rio Grande do Sul (TJ-RS). Agravo de Instrumento70076575331 RS. Relator: Luiz Felipe Brasil Santos. DJ: 02/05/2018. Disponível em: http://www.tjrs.jus.br/busca/?tb=jurisnova\#main_res_juris. Acesso em: 5 dez. 2019.

SCHMOLLER, Francielli; FRANZOI, Fabrisia. A importância da atividade notarial e registral: uma análise da função social e a evolução neste âmbito jurídico. [S. l.], 4 jul. 2018. Disponível em: http://www.cnbsp.org. br/index.php?pG=X19leGliZV9ub3RpY2lhcw==\&in=MTYONjM=\&filtro=1. Acesso em: 22 jan. 2020.

VANIN, Carlos Eduardo. A força probante da ata notarial no CPC de 2015. Disponível em: https:// duduhvanin.jusbrasil.com.br/artigos/643345380/a-forca-probante-da-ata-notarial-no-cpc-de-2015. Acesso em: 23 jan. 2020. 
1 Acadêmica em Direito pela Universidade Tiradentes UNIT. E-mail:

2 Mestre em Educação pela Universidade Tiradentes - UNIT; Doutorando em Educação, pelo Programa de pós-graduação em Educação da Universidade Tiradentes - UNIT; Especialista em Direito Processual Civil pela Universidade Unyanha (BA); Coordenador de projetos de iniciação científica PROVIC/Unit, pesquisador-líder do Grupo de Pesquisa "Gênero, Direitos Humanos e Diversidade Sexual”, CNPq. E-mail:

3 Mestre em Direitos Humanos pela Universidade Tiradentes - UNIT; Advogada; Membro em Diretório de Pesquisa Cadastrado no CNPQ- Novas Tecnologias e o Impacto nos Direitos Humanos, do Núcleo Estruturante do Corpo Docente e da Comissão Disciplinar da Universidade Tiradentes - UNIT; Editora Executiva da Revista Cadernos de Graduação da Universidade Tiradentes. E-mail:

4 Doutor em direito político e econômico pela Universidade Mackenzie (2018); Mestre em Direito, na área de concentração constitucionalização em direito - UFS (2014); Pós-graduado em Direito Civil - UNIT (2005); Graduado em Direito - UNIT (2002); Professor titular da graduação e do mestrado em direitos humanos do PPGD-UNIT e convidado em cursos de pós-graduação; Avaliador de várias revistas jurídicas. Líder do grupo de pesquisa Novas tecnologias e o impacto nos Direitos Humanos

E-mail: contato@diogocalasans.com

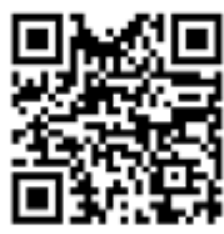

A autenticidade desse artigo pode ser conferida no site https://periodicos. set.edu.br

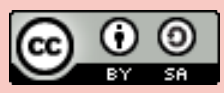

Este artigo é licenciado na modalidade acesso abertosob a Atribuição-Compartilhalgual CC BY-SA

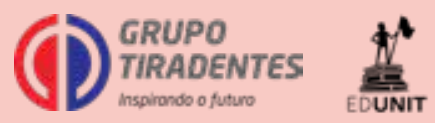

